\title{
Don Quijote, Hamlet y el cogito. Sobre las raíces de la estética en la filosofía moderna
}

\section{Don Quixote, Hamlet and the cogito. On the roots of aesthetics in modern philosophy}

\author{
Vicente SERRano \\ Universidad Austral de Chile \\ vicente.serrano.marin@gmail.com
}

\begin{abstract}
RESUMEN. El artículo compara los dos grandes personajes de Shakespeare y Cervantes con el cogito cartesiano a fin de averiguar si expresan aspectos de lo moderno que este último oculta. En particular se analizan desde la perspectiva de la ausencia, cuya expresión se compara con la pérdida de la metafísica del ser y de la noción de naturaleza premodernas. Se indaga la posibilidad de que en esa ausencia hunda sus raíces la estética de la filosofía moderna.
\end{abstract}

Palabras clave: Estética, modernidad, cogito, metafísica, ser, naturaleza
ABSTRACT. The article compares the two main characters of Shakespeare and Cervantes with Cartesian cogito, to find out if they express aspects of modernity that cartesian cogito hides. In particular are analyzed from the point of view of the absence, whose expression is compared with the loss of the metaphysics of being and the pre-modern notion of nature. It explores the possibility that the aesthetic is rooted in modern philosophy

Key words: Aesthetics, Modernity, cogito, metaphysics, being, nature

El arte ha estado tradicionalmente unido a la verdad, a la verdad moral y a la verdad científica, si bien tal unión no debe pensarse necesariamente en términos tan explícitos e idealistas como los pensó Platón en la Teoría de las Ideas, en la que la belleza, la verdad y la justicia se anudaban; ni tampoco en esa particular reedición moderna del platonismo por los románticos, que aspiraban a reunir de nuevo esos objetos y cuya expresión más clara sea tal vez el memorable comienzo del Endymion de John Keats: «La belleza es la verdad». Tanto la versión platónica como la romántica son idealistas y expresan sólo en forma extrema un hecho que han indagado contemporáneamente disciplinas como la antropología, la lingüística o la sociología del conocimiento. Se trata de un tipo de relación entre verdad, belleza y justicia que durante siglos descansó en estructuras simbólicas que podrían coincidir con lo que a comienzos del siglo xx Dilthey acuñó como visión del mundo 
o Weltanschauung, o con lo que ya en el seno de la filosofía postpositivista de la ciencia, Kuhn llamó paradigma, pero en parte también con lo que había querido expresar Quine al afirmar que epistemológicamente le parecían equiparables los dioses griegos a las verdades de la física moderna (2003, 44). Forzando algo las cosas podría incluso servir la noción de marco en el sentido utilizado por Erving Goffman, pero con la peculiaridad de tratarse de un único marco compartido y que poetizaba la realidad en el sentido en el que el conjunto de las experiencias se hacían depender de ese marco, sobre el que luego se construye la filosofía.

Es desde una consideración como ésa desde donde afirmo que la ciencia premoderna dependió de una concepción estética compartida con el arte, de una visión común a la que se aproximaba de modo distinto, pero que era en lo esencial la misma. No habría mejor ejemplo para ilustrarlo que acudiendo al universo que describe Aristóteles en la Metafísica. Como tal en la Metafisica la aproximación al objeto es «científica», pero el mundo que reproduce es ese esquema, es decir, una representación de lo real compartida, un marco común poetizado: el universo de las esferas con la tierra en el centro, el universo circular y perfecto del mundo supralunar, el mundo cambiante de lo sublunar. Ese cuadro fijo sobre el que se desarrollan los principios explicativos es lo que llamaremos aquí, a falta de otro nombre, el poema del ser, para resaltar esa dimensión estética y en la medida en que los primeros tratados filosóficos en torno a la naturaleza eran formalmente poemas y a la vez su sentido filosófico fue finalmente recogido por Aristóteles en la Metafisica en términos de ser.

La hipótesis es que ese marco tiende a extinguirse en la emergencia de lo moderno y al hacerlo produce una modificación en los modos de representar intuitivamente lo real, o incluso en la posibilidad de representar a la noción misma de naturaleza. Es en ese momento cuando el arte y la ciencia se separan, más allá del distinto modo de aproximación de cada cual respecto del objeto común que era aquel poema primordial o del ser. Se separan porque el fondo común que era el poema del ser desaparece y con él elemento que compartían, el objeto del que hablaban desde lenguajes y puntos de vista diversos. Ese momento es la modernidad. Cuando, tiempo después, nazca la estética como disciplina encontrará su razón de ser en explicar esa separación, en dar cuenta de ella, en situar al arte en el nuevo universo y al margen del discurso científico, es decir, como un discurso autónomo que trata de encontrar un estatuto propio, que se cuestiona una y otra vez sus relaciones con la verdad y con el bien y, sobre todo que, al carecer de la poética profunda que he llamado poema del ser, trata de encontrarla en ella misma o más allá de sí. De ahí que la relación entre arte y realidad se haga cada vez más compleja y que el papel de la ficción cobre un especial protagonismo, pero junto a él, también el de la locura, como límite de la comprensión de lo real. 
No es de extrañar entonces que en Hamlet, en Don Quijote y en la obra filosófica de Descartes, apenas sólo separadas en el tiempo por algunos años, a comienzos del siglo XVII, este tema resulte decisivo. De sus mutuas relaciones podemos aprender mucho acerca las dimensiones metafísicas de la estética en la filosofía moderna. ${ }^{1}$ En Hamlet es la sombra del padre, su espectro, quien reclama a su hijo, quien le inquieta instalado en la conciencia, y quien conduce finalmente la acción de la tragedia, que por eso mismo y desde el comienzo se mueve en una lucha entre la realidad y la ficción. Desde luego que se han hecho muchas interpretaciones acerca del significado de la sombra o del espectro del rey padre, asesinado por el hermano. Desde el psicoanálisis, y en distintas versiones por Freud y Lacan, desde el feminismo, desde la teoría política. ${ }^{2}$ La que propongo es considerar que la sombra y el espectro representan ese poema del ser abandonado, asesinado en la tragedia de Shakespeare. Es su ausencia la que determina la acción, pero transfigurada en forma de delirio, estrechamente vinculada a la emergencia de la locura. También el Quijote es la historia de una locura. El desvarío es su razón de ser, lo que, como en Hamlet, determina la acción y lo que da el sentido a la obra. Esa distancia entre el universo mental de don Quijote y lo que llamamos realidad es lo que una y otra vez, en cada episodio de la novela, como en el conjunto de la misma, puede también interpretarse en términos de ausencia y que sería lo propio de la modernidad emergente. Si don Quijote ve un castellano donde sólo hay un ventero, si ve gigantes donde hay molinos, si a Dulcinea la toma por una bella dama y a los monjes de San Benito por salteadores, es porque en su conciencia sigue operando esa intuición estética de la naturaleza, como opera en la de Hamlet la sombra del espectro. Es una ausencia la que en ambos conduce la acción, la que además les da su fuerza, la que permite reconsiderar y evaluar el mundo.

En El Discurso y en Las Meditaciones Descartes narra el proceso mediante el que la ciencia debe sustituir esa poética del ser, un procedimiento en el que la naturaleza se va desvaneciendo para reconfigurarse al servicio de la máquina del saber que se pone en marcha y convertirse en mera extensión. Si Cervantes y Shakespeare reconsideran la realidad o el mundo desde esa ausencia y al hacerlo ponen en marcha el arte moderno, en cambio lo

${ }^{1}$ De la importancia de las relaciones entre Hamlet y el Quijote para la Europa moderna da cuenta de manera explícita Salvador de Madariaga al afirmar que el paralelismo entre ambos es tal vez «una de las vías más claras de aproximación no sólo al conocimiento de cada uno de ellos, sino también incluso para el conocimiento de Europa y de sus problemas permanentes» (Madariaga, 1964: 7). El ya clásico ensayo de Turgeniev insiste, desde otra perspectiva en la misma idea (Rinkus, 1975: 76) y Harold Bloom afirma que la influencia concertada de Shakespeare y Cervantes define el curso ulterior de la literatura occidental (Bloom, 2005: 68).

2 Remitimos en este caso al artículo del pensador español Javier Roiz (Roiz, 1994), cuya lectura inspiró en parte este trabajo. 
que Descartes nos propone es organizar y explicar esa ausencia para abrazar una nueva realidad, como un resultado en el que esa ausencia se justifica y se consuma. ${ }^{3} \mathrm{Si}$ siglo tras siglo se vuelve Descartes para ver en su obra simbolizada la emergencia de la modernidad, es precisamente porque ninguna otra consuma mejor la supresión y explicación de la naturaleza en que la modernidad consistiría. La duda metódica, además de las habituales e innegables interpretaciones en torno al clima escéptico del Renacimiento ${ }^{4}$, más allá de las consideraciones en torno a la búsqueda de la certeza del saber, representa sobre todo y ante todo el relato perfecto en el que se expresa la modernidad como ausencia de esa poética del ser. Pero allí donde Shakespeare y Cervantes extraen un tesoro de consecuencias, la riqueza conflictiva, confusa y ambigua que surge de esa ausencia, en Descartes se extiende únicamente un certificado de defunción y se levanta acta de ese proceso. Desde luego que también Descartes construye un relato, como él mismo nos recuerda, pero su diferencia no está sólo en el género literario, en la voluntad supuestamente metafísica y filosófica cartesiana, con ser esta también decisiva. Su diferencia consiste en que donde Shakespeare y Cervantes ponen sus recursos al servicio de la crítica y nos mueven a la reflexión y a la toma de distancia respecto de las fronteras entre la realidad y la ficción, entre la verdad, la belleza y la justicia, en Descartes se trata finalmente de eliminar cualquier resquicio de crítica, se trata de sancionar la verdad, ese terrible fundamentum inconcussum. A partir de él la belleza y la justicia no están ya en el lugar de la verdad ni deben buscarse en ella. La ciencia se construye al margen de la justicia y de la belleza, abriendo así un abismo entre ellas que los filósofos de la modernidad visitarán afanosamente y desde el que cabe explicar el germen de los posteriores desarrollos tanto de la ética como la estética de la modernidad.

Cuando en el acto I de Hamlet, el príncipe le dice a Horacio: ¡hay algo más en el cielo y en la tierra. Horacio, de lo que ha soñado tu filosofia! (Shakespeare, 2003: 119) no está sino dirigiéndose a la filosofía de la modernidad que en breve comenzará a condensar Descartes y que, pasados los siglos, se ha aplicado de muchos modos al propio Descartes y a lo que su gesto representó. Aunque no podemos encontrar una frase equivalente y tan ajustada la novela de Cervantes, toda ella es, sin embargo, una expresión de lo enunciado por Hamlet en su frase a Horacio. La belleza, la verdad y la justicia van en él de la mano y es su articulación, más allá de lo que el lector puede entender por realidad, la que da sentido al sin sentido del héroe. Deshacedor de entuertos y de sinrazones se denomina a sí mismo el caballero de la triste figura, caballero que entiende su tarea como la del amor «que

${ }^{3}$ En ese sentido parece desenfocada la visión del cartesianismo como una filosofía del espejo, que de manera tan brillante presentó Richard Rorty (Rorty, 1979).

${ }^{4}$ Remitimos a la ya clásica interpretación de Richard Popkin (1983: 259 y ss.). 
todo lo iguala», y en el que van de la mano la justicia y la verdad, iluminados por la belleza de Dulcinea. No hay duda de que esa verdad que una y otra vez aparece mentada en la novela es también veracidad en sentido moral, sinceridad del que no miente. Pero esa veracidad de Don Quijote apunta a otra más profunda que va más allá de la veracidad moral. Su permanente contraste con la verdad sensible aparentemente menos dudosa, su victoria ante la materialidad incontestable que le deja molido a golpes, le humilla y le fatiga de forma incansable, sitúa la verdad de don Quijote en el mismo nivel y a la misma altura que la verdad más sensible y material con la que compite y a la que una y otra vez niega y supera. Lo que está en juego es la condición del mundo y del universo todo, su comprensión, su consistencia: la verdad.

Tanto esas cosas que hay en el cielo y la tierra y que la sabiduría de Horacio desconoce, como las ilusiones del caballero manchego se enfrentan abiertamente a la verdad de la ciencia, no para negarla sin más, sino para rebasarla, para redefinirla en una articulación más amplia donde la belleza y la moral se reúnen con ella. Y en ambos casos lo hacen desde una ausencia. En Hamlet esa ausencia toma la forma inicial de un espectro, pero a medida que la tragedia avanza se confunde con los afectos que luchan en el interior del príncipe de Dinamarca, y descubrimos que son su mirada, su pensamiento, su dolor, su voluntad, quienes soportan esa verdad y la expresan hasta el momento de su muerte. Y ése es igualmente el caso de don Alonso Quijano, pues su verdad, la verdad, es un anhelo, un ensueño, un complejo de afectos, pensamientos, reflexiones de un hombre que cualquiera tendría por juicioso y culto si no fuera precisamente por ese enfrentamiento que le lleva hacia una verdad invisible y ausente. Pero ni Cervantes ni Shakespeare niegan la verdad de la ciencia. Al contrario, porque la afirman y la reconocen se ven obligados a enfrentarse con el tema central en torno al que articulan la ausencia: la locura.

También Descartes construye un relato en el que el tema central es el de la frontera entre lo real y lo ficticio. Tanto el Discurso como las Meditaciones poseen en ese sentido un estrecho parentesco con Hamlet y el Quijote, que le preceden en unos pocos años, apenas unas décadas. Esa afinidad no puede ser casual. Más allá del resultado y del género en cada caso hay muchas analogías entre los tres relatos. Donde Hamlet apela al espectro y en su momento a la ficción y a la imaginación para acceder a la verdad, y donde don Quijote camina de la mano de su imaginación cuestionando la realidad de su entorno, Descartes imagina también un universo en el que se pone en cuestión la realidad misma y de un modo radical. El cogito cartesiano, ese yo desnudo al que llega después de un camino de duda, no es menos ficticio que el espectro de Hamlet o las sucesivas ilusiones en las que el caballero de La Mancha interpone entre él y lo que le presentan los sentidos. Descartes, y en eso su novela se parece más a la de Cervantes, también nos relata 
un camino y en ese camino, su método, se despoja también de lo que sus sentidos le dicen, de la verdad aparente que le rodea.

El experimento mental que la historia de la filosofía nos enseña como duda metódica, puede muy bien ser tal desde el punto de vista de la epistemología, pero en su sentido más estricto, la presentación que Descartes hace de él, tanto en las Meditaciones como en el Discurso, es un relato en el que la imaginación sustituye el mundo real por un universo imaginado, en el que incluso las verdades de la matemática y de la ciencia son sometidas a las reglas imaginarias. Abstrayendo ahora de los fines que con ello persigue Descartes y de la carga que inevitablemente asociamos a la historia de la filosofía, lo cierto es que el cuento cartesiano, en su condición de fábula, que es el término que le da Descartes al Discurso, no se aleja demasiado de la fábula cervantina. Lo que le separa es que se trata de una fábula al servicio de otra cosa, en este caso al servicio de la verdad de la ciencia. Sólo por eso, porque lo leemos a la luz de la filosofía y de la ciencia cartesiana, no podemos considerarlo un relato sin más, no podemos considerarlo arte. Pero si hiciéramos nosotros a su vez el esfuerzo de abstraer de ese contexto y de esa finalidad para la que fue escrito, si lo consideráramos como una obra estética sin más, lo tendríamos por un extraño relato en el que un personaje a la luz de la lumbre es capaz de transformarse en virtud de su imaginación, llevándole con él a regiones desconocidas, irreconocibles en la realidad cotidiana. Desde ese punto de vista estrictamente formal no hay mucha diferencia entre la verdad del espectro, la del hidalgo manchego o la del filósofo en su gabinete. Los tres cuestionan la realidad ordinaria y lo hacen mediante la imaginación. Veremos más adelante que las analogías no se detienen ahí, pero por el momento mi objetivo es sólo situar el cuento cartesiano en ese mismo plano y recordar esa dimensión suya como un relato cuyo tema central es el de los límites entre la realidad, la ficción y otros objetos afines como la locura, el delirio y el sueño.

Pero ese tema que comparten, y que es tal vez el tema mismo de la modernidad, lo abordan desde dos ámbitos bien diferentes. Los poetas actúan como tales y construyen una obra de arte, el filósofo y matemático construye su relato como una justificación de la ciencia y frente a la ciencia premoderna, lo que él llama escolástica, como una justificación del nuevo paradigma científico que él mismo está colaborando a edificar y que con el tiempo acabará siendo el dominante, el de la ciencia físico-matemática moderna. En los poetas la imaginación navega y se aleja de las apariencias en búsqueda de las huellas de una ausencia o directamente refleja esa ausencia, haciendo de la locura, si bien de modos diversos, el vehículo que la instala sobre la realidad, la sombra de esa ausencia que acompaña a las conciencias de sus protagonistas, desde las cuales se proyecta sobre el mundo y nos conduce así a nosotros, sus lectores, a una meditación inquietante. En el 
filósofo, en cambio, la imaginación ayuda inicialmente también a huir de las apariencias, del engañoso universo de los sentidos, pero al final de su viaje la ausencia y su sombra acaban por disiparse y el mundo de los sentidos reaparece de nuevo sometido de forma demoledora e incontestable a la claridad y la distinción, ajeno entonces a esa sombra, desechando los restos de esa ausencia. La imaginación como tal le sirve entonces para disipar cualquier sombra, cualquier espectro, para negar esa supuesta ausencia. $\mathrm{Su}$ verdad es la negación de la ausencia y esa negación es a la vez la afirmación de la verdad de la ciencia y el mundo moderno. Donde los poetas convierten a la ausencia en la vida del poema, el filósofo-matemático simplemente la suprime.

Siendo como son contemporáneos comparten el mismo universo y el mismo problema, pero su solución es justamente la contraria. Sería injusto pensar que Cervantes hace un elogio de la locura sin más y que desprecia la realidad, la realidad de la ciencia, diríamos hoy, porque no sin motivos su novela puede considerarse y ha sido considerada como realista (Varela Iglesias, 2007). No la niega, ni la cuestiona, simplemente la hace convivir con eso que hemos llamado ausencia, y es en ese convivir donde la locura sirve de puente y nos abre las vías para ver esa realidad con otros ojos. Lo mismo cabe decir de la tragedia de Shakespeare. La realidad expresada en la muerte, en el conflicto, en las pasiones, en el dolor, no es cuestionada, pero sobre ella se arroja una luz que procede del alma de Hamlet, de su locura fingida o no fingida, del juego de la ficción, y a su luz podemos ver esa misma realidad con otros ojos. No nos dice que no se dé, que no sea cierta la filosofía de Horacio, nos dice, simplemente que hay más cosas que esa filosofía no alcanza y en ese sentido son literalmente una ausencia para ella. Descartes en cambio evalúa todos los objetos posibles que estarían más allá de la ciencia, si bien llega a ella después de haberlos desechado. El saber y la verdad de Descartes se construyen al margen de la ausencia, porque la ausencia es nada.

Pero analicemos más de cerca esa ausencia que es nada para Descartes, y que como tal es desechada de lo real. El camino recorrido por Descartes fue inverso al que aparece en su relato. Antes de su relato existe una máquina del saber que él ya ha descubierto, un procedimiento, una técnica, un ejercicio. Tres años después de la muerte de nuestros poetas, es decir, en 1619 , tenemos constancia de que Descartes ha descubierto un artificio que será con el tiempo lo que hoy conocemos como geometría analítica (Turró, 1985: 230-235). Todo el resto de su obra gira en torno a ese artificio y su saber, lo que él llama el saber, depende de ese artificio tanto su funcionamiento como su resultado. Su relato, lo que llamamos su relato, que es en realidad una filosofía de la ciencia entendida como una explicación de los 
principios de funcionamiento de esa máquina ${ }^{5}$, se reduce en ese sentido a hablar de la máquina, y debemos concluir entonces que esa realidad que queda fuera, esa ausencia que desecha, tiene que ver con aquello que no es explicado por la máquina o que no puede resolver la máquina. Aunque Descartes fue original en sus planteamientos, genial en la articulación y en la expresión de los mismos, sabemos que esa concepción suya no fue una ocurrencia, sino que era ya la de la época de modo dominante y creciente, lo que se denominó una ciencia de ingenieros, que venía gestándose a lo largo de los últimos siglos. ${ }^{6}$ Él supo como pocos organizarla y venderla, en un momento en que esto era ya posible, incluso con muchas cautelas. Un contemporáneo suyo, y también contemporáneo de nuestros poetas, lo había expresado a su modo, en una frase que todavía utilizaron Adorno y Horkheimer en su Dialéctica de la Ilustración, como síntesis de lo moderno: saber es $\operatorname{poder}^{7}$ (Adorno y Horkheimer, 1998: 60). La realidad es poder o el resultado del poder. Es poder, es acción, es una máquina, es el resultado del poder, de la acción y de la máquina. Todo lo demás es ausencia.

Esa es la ausencia que constatan sus contemporáneos los poetas y desde la que construyen las primeras expresiones del arte moderno. Mediante la locura, sus poemas, tragedia y novela, cantan y describen la ausencia. Pero no pretenden volver atrás, porque constatan que no hay vuelta atrás. Tampoco se lamentan sin más, simplemente imitan la ausencia, pero en la medida en que lo es su arte no es ya imitación, porque el modelo a imitar, ese poema primordial extinto, ya no existe. Por eso la locura y el fingimiento, la locura o el fingimiento dentro de la ficción. Si en la Poética Aristóteles insistió en considerar la imitación como elemento esencial del arte fue porque el modelo a imitar existía bajo el nombre de naturaleza. En cambio, lo que nuestros poetas cantan es la ausencia de la naturaleza, o más bien cantan desde esa ausencia estilizada respectivamente en el espectro y en la muerte que da lugar a la melancolía y a la locura, fingida o no de Hamlet, y en la distancia que la locura del hidalgo interpone entre él y el mundo. La mirada de ambos recae sobre el mundo pero está atravesada de esa ausencia. La justicia, la belleza, la verdad resultan entonces de la imitación de la ausencia, pero una imitación de la ausencia no es ya imitación, es otra cosa: la cosa del arte moderno.

Tal vez el mejor modo de entender lo que decimos, de acercarnos a esa cosa del arte moderno, sea precisamente regresando de nuevo al relato cartesiano, que formalmente juega con los mismos elementos y tiene el mismo objeto. Su relato, su poema metafísico, podríamos decir, va descomponiendo la realidad de un modo sistemático y ordenado y, como ya hemos señalado. Cualquiera lo tendría por locura si no fuera lo que es, un recurso literario

${ }^{5} \mathrm{Y}$ en ese sentido se puede compartir la afirmación de Clarke con arreglo a la cual Descartes es un científico empirista que compone algunos relatos (Clarke, 1986: 16 y 29).

${ }^{6}$ Según la expresión de Laberthonière que irritó un tanto a Koyré (Koyré, 1980: 2).

${ }^{7}$ La citan como hilo conductor dominante de su reflexión amarga sobre la Ilustración. 
situado en el prólogo de un libro científico, como es el Discurso, o si no se presentara como el resultado de la filosofía y de la ciencia de un autor que ha adquirido ya el prestigio que Descartes poseía en el momento de publicar las Meditaciones. El resultado final del poema, que todos conocemos, no deja de ser una monstruosidad que hubiera sido impensable, abominable, para las mentes de la Antigüedad y para la mayor parte de las visiones del mundo de distintos pueblos y culturas. El universo queda reducido a la extensión de un desierto interminable bajo la mirada atenta de un monstruo no visible capaz de operar sobre él: extensión y pensamiento. Si comparamos este inicio metafórico del mundo moderno con otras teogonías podríamos pensar que hemos regresado a un estadio de terror en el que el caos del mundo ha sido sustituido por una especie de desierto, que es desde luego el desierto de lo real, aunque ni siquiera necesariamente en el sentido lacaniano que recuerda Žižek evocando una frase de Matrix (Žižek, 2005). Ese interminable desierto de lo real se adorna después, desde luego, con todas las cualidades que adornan el mundo, que queda restablecido en su consistencia ordinaria y cotidiana. Esa consistencia es equivalente a la de los venteros, a la de los cerdos y ovejas, a la de la Maritornes del Quijote, o a la Realpolitik que representa el político usurpador, el tío de Hamlet. Pero del mismo modo que en el Quijote y en Hamlet la ausencia arroja una nueva luz sobre esa realidad y nos ofrece así la cualidad del poema moderno, en Descartes la consistencia final de ese universo ordinario depende de aquel desierto de lo real, precisamente porque lo real reside en él. Si en la mirada de Cervantes y Shakespeare hay un plus sobre lo real que trata de representar la ausencia, en la mirada cartesiana ese plus se convierte en un minus. Lo que Descartes presenta y representa es ese minus, la reducción del universo a la pura extensión, lo que es lo mismo que decir que lo real representa la ausencia de la naturaleza y de su poema esencial.

Es esa ausencia que los tres comparten, la que da sentido a la locura de don Quijote, la que explica el papel del espectro en Hamlet, y también la que determina la medida de la verdad en Descartes. Por eso la verdad de los primeros desborda el universo de la cordura y del buen sentido cartesianos, por eso en ellos la verdad se sitúa en esa confusa frontera donde están en juego además la belleza y la justicia, perdidas en la ausencia a la que tratan de imitar. Pero también por eso en Descartes la verdad desnuda sin naturaleza, el desierto de lo real, se ha desprendido definitivamente de la justicia y de la belleza constatando así el nacimiento de la ciencia moderna, en la que la belleza y la justicia se desanudan de la verdad. La historia de la ética y de la estética moderna es la historia de los esfuerzos por repensar la justicia y la belleza al margen de la naturaleza, del poema de la naturaleza y del ser, una vez asumida su desconexión respecto de la verdad de la ciencia, de la verdad, de la realidad. En un momento maduro de la modernidad se constata bien lo que decimos mediante un análisis detenido de las relaciones 
entre las tres Críticas kantianas, como se constata bien el problema de la ausencia en ese extraño objeto filosófico que es la llamada cosa en sí kantiana.

Pero hay un modo más sencillo de reconsiderar la cuestión. Las historias de la filosofía recogen una distinción común y habitual entre los filósofos que van trabajando ese árido desierto de lo real en los comienzos de la modernidad. Nos referimos a la distinción entre las llamadas cualidades primarias y secundarias. Sólo las primeras tienen lugar en el nuevo estatuto del saber dictado por la ausencia de la naturaleza. Las cualidades primarias son aquéllas susceptibles de ser cuantificadas, medidas, traducidas al lenguaje de las matemáticas, en cuyos caracteres, según el dictum de Galileo, estaba escrita la naturaleza. Todas las demás, las llamadas cualidades secundarias, las cualidades propiamente dichas frente a las cantidades, aquéllas que constituyen la materia del arte, no pueden ser objeto de la ciencia, de la verdad, del saber y simplemente se evaporan. Pero con ellas desaparece una ciencia que durante siglos se había basado en cualidades. Por decirlo de un modo aún más claro y en términos de la filosofía: desaparecen el ser y con él todos los aparatos conceptuales que dependían de él y le explicaban. Pero el ser, a pesar de su aparente abstracción, desde los griegos y da lo mismo ahora en cual de sus versiones, era lo que se extraía del poema de la naturaleza. No es casual que la mayor parte de los que consideramos tratados filosóficos de los presocráticos se presentaran como poemas cuyo título era invariablemen-

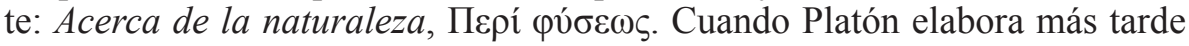
su metafísica, convierte a su vez a la naturaleza en una imitación respecto del universo de las ideas: ¡una imitación! Exactamente lo que Aristóteles, su más destacado discípulo, definía como lo propio de la poética. La metafísica de Aristóteles ciertamente no se recreaba en el poema, pero obtenía sus principios a partir de la visión ofrecida en el poema, que no cuestionaba. A esa visión se la podría llamar la poética primordial, y es esa la que desaparece con la distinción entre cualidades primarias y secundarias. ${ }^{8} \mathrm{Y}$ no es que las matemáticas no hubieran tenido una extraordinaria importancia en el mundo antiguo, sólo que esa importancia dependía a su vez de esa dimensión estética y se vinculaban a ella. En los pitagóricos los números eran nada menos que el principio de las cosas, pero tanto los números como las cosas

8 No es de extrañar entonces que Kant afirme del ser que es sólo la posición absoluta o la cópula del juicio, aquello que une sujeto y predicado. Y al afirmarlo así afirma una profunda verdad, pues el poema del ser era también la posición absoluta a partir de cuya pintura se extraían los principio del saber o el ser era el nexo universal del poema, tal como relataba Empédocles en su poema. Sólo que en Kant, extinta la naturaleza, la posición absoluta remite a la voluntad, como ocurre en Fichte y sus epígonos o en los pragmatistas más tarde, o en la voluntad de poder, y la cópula remite sólo a un operador lingüístico. Por lo mismo tampoco es de extrañar que en Hegel el ser y la nada sean exactamente lo mismo, lo más vacío, como lo serán por lo demás en Sartre. Ni tampoco es de extrañar que Heidegger luche afanosamente por recuperar el ser en términos de ausencia. 
resultaban indisolubles de una intuición básica, eso que llamamos el poema primordial y eran entonces una parte del mismo, cobraban sentido en su seno. También en su discípulo Platón los números y las matemáticas eran especialmente importantes, pero en Platón tenían consistencia únicamente anclados a esa poética primordial.

La cuestión entonces no es sin más la prioridad de las matemáticas o el uso dado a las mismas, ni siquiera la capacidad de medir y predecir que solemos asociar a las ciencias, porque también la ciencia aristotélica trataba de hacerlo, la cuestión es que esa capacidad de predecir y el uso de las matemáticas y la apelación a la experiencia propia de la moderna ciencia, necesitaron prescindir de una intuición estética, la cuestión es que las matemáticas se quedan solas y extinguen cualquier otra dimensión de la realidad. Y aunque uno puede experimentar cierta belleza en una ecuación, en el hecho mismo de operar, ni la belleza ni la justicia de las cosas humanas tienen posibilidad de germinar en las series de números y de igualdades. Es lo que todos sabemos, que el saber de las matemáticas es un saber formal y vacío. Ciertamente la ciencia moderna está lejos de consistir sin más en un mero juego vacío de cifras, porque las integra y las aplica a determinadas operaciones, experiencias y experimentos, cuyo resultado llamamos verdad. Ese resultado es lo material. Pero no imita, no reproduce, no representa, simplemente opera mediante cifras y obtiene resultados. Ese modo de aproximarse a la realidad no es nuevo ni exclusivo del mundo moderno. Desde el hombre de las cavernas hasta nuestros días la especie humana siempre ha necesitado medir, operar conforme a cálculos, y obtener resultados. Hasta la tecnología más elemental se atiene a eso. Las pirámides de las distintas culturas, la gran y admirable ingeniería de la vieja Roma, la muralla china, son ejemplos magníficos que implicaban ese tipo de saberes. Lo que aporta la ciencia moderna es la absolutización de ese tipo de operaciones de medición y cálculo para obtener resultados. Pero al convertirlo en algo absoluto ocupa la mirada de lo que propiamente hablando se llamaba contemplación en el universo. Es una obviedad hoy para cualquier persona culta que la ciencia carece ya de intuiciones y se basa únicamente en ecuaciones de un elevadísimo nivel de abstracción. Cuando Heidegger afirmaba que la ciencia no piensa, se refería en realidad a eso, consideraba el pensamiento como contemplación. No es de extrañar entonces que considerara la historia de la filosofía como olvido del ser y que, heredero del Romanticismo, buscara afanosamente hallar el ser y la verdad en el arte, que buscara ese poema primordial y apelara a la Dichtung, esa palabra primordial como lugar del filosofar (Heidegger, 1989: 29 y 30). Pero lo que Heidegger obvia es que esa ausencia no es la de la metafísica de Occidente, a la que denomina metafísica de la presencia, sino sólo la marca distintiva de la modernidad. Cuando insiste una y otra vez en considerar toda la metafísica de Occidente como metafísica de la presencia y olvido del ser no sólo está trasladando más allá 
de la modernidad lo que es sólo la condición fundamental de lo moderno, sino que está además trasladando equivocadamente su nostalgia del ser, su duelo por la pérdida del ser, como hicieron los románticos, a toda la historia del pensamiento. Con ello obvia la especificidad de la ausencia moderna y en su lugar se obstina en ver una metafísica de la presencia, donde hay sólo una metafísica de la ausencia. Sueña con recuperar el ser en términos de ausencia y de este modo se priva de una adecuada comprensión de lo moderno y de sus relaciones con lo premoderno, incluso a pesar de la asombrosa lucidez de sus descripciones y aproximaciones.

Lo que Descartes nos ofrece en su relato no es, entonces, una nueva vuelta de tuerca de una supuesta metafísica de la presencia, ni siquiera de la representación, sino sólo la expresión más cruda del vaciamiento de esa dimensión estética de la que dependía la naturaleza. El resultado es entonces ese paisaje desértico que no es representación sino sólo reducción, que no puede imitar nada, ni es espejo de ninguna naturaleza porque con el poema del ser cae también la naturaleza. Porque allí donde no hay nada que imitar no hay tampoco representación posible. Por eso la comparación del relato cartesiano con Hamlet y Shakespeare es pertinente, porque a la luz de la misma se aprecia con claridad por qué ambos y de qué modo representan el nacimiento del arte moderno. Decimos del arte y no de la estética, porque ésta nacerá más tarde. Hamlet y Don Quijote representan aquella obra de arte donde la imitación no es ya posible, donde la imitación que es posible lo es sólo del vaciamiento. La justicia y la belleza en forma de ausencia son su máxima expresión. En lo sucesivo el arte, cuando sea valioso, sólo representará a ambas en forma de ausencia, con el tiempo expresando lo feo, la crueldad, el mal, por el momento sólo como ese interrogante melancólico que nos llena de perplejidad al leer las páginas de Cervantes en su camino por las brumas de la ausencia, o los diálogos de Hamlet en el interior tormentoso en el que cree fingir la locura a partir de sus conversaciones con un espectro, con el espectro de una ausencia.

Pero hay todavía una cuestión en la que la analogía entre los tres poetas de la modernidad y sus respectivos relatos en torno a la ausencia del poema primordial se hace más precisa e hiriente: el inevitable y agotador mito del sujeto, en torno al cual se ha querido tejer la modernidad. En las últimas décadas esa cuestión y su pretendida superación se han vinculado estrechamente a la cuestión del lenguaje. En la consideración que podemos llamar clásica del asunto, el sujeto habría hecho las veces del poema del ser. No es casual que la locura sea el centro de Hamlet y del Quijote, como no lo es tampoco que la afirmación del sujeto cartesiano lo sea en términos de exclusión de la locura, en cuanto hipótesis extrema como quería Foucault. Hay una estrecha relación entre el juego de la locura en cada una de esas obras y la exclusión cartesiana de la locura. En una primera aproximación ya hemos insinuado más arriba que la locura como recurso literario obedece al proble- 
ma fundamental en torno a la cual giran las tres obras, que es también el de la propia condición de lo moderno a la que responden. Y esa relación no se da únicamente en el hecho de que la locura sea la máxima expresión mediante la que un sujeto cuestiona el orden de lo real, de la norma, en este caso de lo real moderno, sino sobre todo porque está estrechamente vinculada a eso que hemos llamado el sujeto y es determinante de la subjetividad.

En Descartes la locura aparece a lo largo de la trama como un recurso literario en el que quedaría expresado el cuestionamiento de la realidad, la máxima manifestación de la duda, una hipérbole que condensa, como afirma Derrida (1989, 47 y ss.), la duda que inicialmente Descartes habría ido depositando en los sentidos, en el sueño, o incluso en las verdades matemáticas. Desde esa interpretación, como desde la de Foucault ${ }^{9}$, el genio maligno aparece como el personaje en el que la locura hiperbólica amenaza a la razón, a la nueva verdad que Descartes pretende ofrecernos, la de ese desierto de lo real, la verdad ajena al poema del ser y que es propia de la ciencia moderna. Y sabemos que esa amenaza es finalmente conjurada mediante el yo cartesiano, mediante el cogito y con la ayuda de la divinidad que descubre Descartes en el interior del mismo. Alcanzar ese territorio, el de la verdad, el del saber de la ciencia, exige pues tachar la locura y con ella al genio maligno que es su máxima expresión. La locura aparece inevitablemente como un cuestionamiento de lo real sin el cual le reapropiación de éste por el yo cartesiano sería insuficiente e ineficaz. Una vez alcanzado el objetivo, la locura debe ser abandonada o situada como lo más opuesto a la verdad, como lo otro de la verdad.

En Don Quijote y en Hamlet ocurre exactamente lo contrario: en ellos la locura es el vehículo de la verdad, de esa verdad que asume la ausencia y que trata de expresarla. En el caso de Hamlet el estatuto de la locura es un clásico problema de interpretación. Son muchos los momentos de la tragedia en los que Hamlet mismo reconoce que su locura es sólo fingida y que su objetivo es mediante ella generar la confusión a sus enemigos, con el fin de que emerjan la verdad y la justicia. La locura aparentemente es un recurso más del que Hamlet se serviría para alcanzar sus objetivos. Pero las cosas no son tan sencillas, porque ese fingimiento productor de verdad, que a su vez cuestiona lo real en sí mismo, no deja de ser resultado de un elemento tan irreal como la locura. El espectro del padre y sus palabras al hijo son las que determinan el fingimiento de la locura. ¿Qué estatuto dar al espectro? ¿Qué relación guarda con la locura? Shakespeare es ambiguo al respecto. La primera aparición del espectro en el acto primero no es ante Hamlet sino a

9 En Historia de la locura en la edad clásica hay una inmediata y directa relación entre la emergencia de la locura moderna y el sujeto cartesiano como su exclusión (Foucault, 1976 I: 78). Es precisamente este tratamiento dado por Foucault el planteamiento que criticó Derrida en una conferencia a la que asistió Foucault, quien guardó silencio durante años. Sólo después en apéndice respondió de modo directo a las críticas de su colega. 
Horacio y a los guardias. En su segunda aparición, sin embargo, es Hamlet el único receptor y es a él a quien únicamente habla. Cuando en el acto quinto vuelva a aparecer y Hamlet le habla ante su madre, la reina, viuda del espectro, ésta no le ve. El espectro produce, pues, distintos efectos en función de los personajes. Sólo resulta supuestamente visible ante el círculo de confianza de Hamlet, pero se niega a hablar y en realidad en esa aparición inicial frente a terceros sólo busca atraer a Hamlet. En su aparición final junto a la reina y madre ella no le percibe. Por lo demás la función del espectro es hablar a Hamlet, es el discurso. Es a causa del discurso del espectro, reservado exclusivamente al príncipe Hamlet, por lo que éste decide fingir la locura y pone en marcha todo el dispositivo de la tragedia. Esa locura fingida depende entonces de un discurso únicamente accesible a Hamlet y que es el discurso de la verdad, pero de una verdad no visible y oculta, ausente, y que finalmente sólo aparecerá, al final de la obra, en forma de ficción, de representación y fingimiento. La verdad en su origen depende del discurso de un espectro, y en su aparición final de la representación y la ficción de un loco que se finge como tal, por tanto también de un discurso. La verdad como tal no aparece, su condición es la ausencia evocada mediante el espectro o mediante el arte o por ambos, y su intermediario es Hamlet que se finge loco y que cree no estarlo, pero que tal vez lo está sin él saberlo. La locura y el arte se vinculan, pues en la función de la verdad, de una verdad que no está, que se desplaza en el territorio de la ausencia y del arte. El sujeto que la enuncia está lejos de ser un sujeto estable y sólido.

En la novela de Cervantes también la ficción y la locura se fusionan de un modo estrecho y combaten con la realidad, o mejor la reconstruyen en distintos planos a través de un estatuto ambiguo de la subjetividad, como se ha recordado tantas veces. El autor y narrador, el mismo Cervantes, aparece en distintos momentos como ajeno al escrito, como ocurre ejemplarmente en el escrutinio, donde su obra Galatea es salvada del fuego. Aunque su presencia como narrador es constante, en realidad no deja de depender de otro autor fingido, Cide Hamete Benengeli, a partir de cuyo relato se continúa la historia. Desde ese momento se nos reitera que lo que se cuenta es fruto de la imaginación y de la invención, a pesar de que en los capítulos anteriores se había afirmado que el objetivo era no apartarse en nada de la verdad. Por si esto no fuera suficiente esa condición ambigua entre lo real y lo imaginado se complica y se hace más profunda a medida que se avanza en el curso de la historia, cuando tanto el autor como los personajes se encuentran consigo mismos como verdaderos en cuanto personajes ficticios, introduciéndose así un nuevo recurso que desplaza la cambiante frontera entre lo real y lo fingido. Lo llamativo es que el vehículo para esos desplazamientos y para ese juego entre realidad y ficción es siempre la propia condición de los sujetos, que no se limita ya a la condición del héroe, sino que abarca también a la de los autores. Lo único estable es entonces el discurso, en cuyo interior 
surgen nuevos discursos, nuevos cuentos en el marco del cuento. La condición misma de don Quijote aparece desdoblada incluso más allá de lo anterior, multiplicada en su interioridad y precisamente mediante el juego entre la ficción y la reflexión del personaje sobre sí mismo, entre el Quijote y Alonso Quijano, especialmente a medida que el relato avanza hacia el final, hacia la muerte, como recuerda de modo sobrecogedor don Miguel de Unamuno en su Vida de Don Quijote y Sancho (Unamuno, 1914: 450). Y para terminar el cuadro la figura de Sancho, la contrafigura de Sancho. Mucho se ha repetido acerca del papel asignado a uno y otro, a don Quijote y a Sancho, como representantes en cada caso de la ficción y de lo real. Pero con ser cierto eso, cabe considerar también que inseparablemente de ese rol respectivo es la propia definición de la subjetividad la que está en juego, como no podía ser de otro modo si asumimos que el estatus de lo real y del delirio es en la modernidad inseparable de la condición del sujeto. Las fronteras entre el delirio y el sentido común están lejos de ser claras en ambos y repartidas de ese modo tan nítido. Si bien es cierto que el peso del delirio parece llevarlo don Quijote, bien mirado no es menor el delirio de Sancho, que invariablemente carece de las alteraciones en lo percibido que justifican el delirio de su señor, y no obstante asume el discurso de su amo, incluso a pesar de las evidencias y de sus propias afirmaciones que reiteran una y otra vez que para él no hay castillos, sino ventas, no hay gigantes sino molinos, no hay ejércitos sino rebaños, no hay caballos sino asnos y que espera convencido gobernar la ínsula que don Quijote le ha prometido. Su discurso realista y juicioso está atravesado por el delirio del amo, y el de éste a su vez atravesado de sentencias llenas de sentido y de sabiduría que compiten en ello en ocasiones con las de su escudero. Al igual que ocurre en la tragedia de Shakespeare la subjetividad es sólo un movimiento oscilante navegando en las aguas turbias donde se juntan la realidad, la ficción y el sueño. Es el lenguaje entendido como ese discurso del espectro del padre o como esa fantasía básica de don Quijote, evocador de la ausencia, el que determina la subjetividad y la alimenta.

El cogito, en cambio, una vez alcanzado, elimina cualquier instancia que le desborde, de la que pueda depender, que evoque un universo más allá de eso que hemos llamado el desierto de lo real. Es cierto que de su interior extrae la divinidad perfecta que le garantice su relación con el mundo y que le ponga a salvo del engaño o incluso del autoengaño. Pero es precisamente esa divinidad garante y salvadora la que elimina finalmente el juego entre lo real y lo imaginario, entre lo ficticio y lo soñado, ese juego en el que está depositada la verdad de los poetas, la verdad que expresan en forma de ausencia. Por eso en Descartes sólo queda esa otra verdad desnuda, no sometida a duda, el muñón espiritual de la subjetividad moderna, de lo que ha pasado por ser la subjetividad moderna, inmóvil y desafiante, castrada y 
estéril, incapaz de comprender el discurso moral ${ }^{10}$ o de percibir la belleza, enterrada en la claridad dura e impermeable de un cristal que veda el acceso al poema del ser y sobre la que dibuja el simulacro del mundo en esa superficie vacía sobre la que trazar las ecuaciones y operar con las matemáticas. Se cita con frecuencia aquel fragmento en el que Descartes nos dice que el cogito es «una cosa que duda, que entiende, que afirma, que niega, que quiere, que no quiere, que imagina también y que siente» (Descartes, 1977: 26). Pero se trata sólo de un flatus vocis, una representación plana, sin fondo, literalmente plana en el sentido en que es plana la representación geométrica sin dimensiones. Donde el arte había descubierto la perspectiva, la afirmación cartesiana se limita al plano bidimensional. Hamlet y el Quijote incorporan en cambio esas dimensiones que los pintores habían puesto en marcha algunas décadas antes. Resulta en ese sentido interesante constatar que la perspectiva se convierta para los pintores una obsesión casi en los mismos años en que la ciencia moderna está a punto de constituirse. Es la intensidad más allá de plano de la ciencia lo que tratan de reflejar en una manifestación del arte moderno que corre paralela a las obras de Shakespeare y de Cervantes y que busca imitar la naturaleza apenas antes de que desaparezca definitivamente. Pero lo que en ellos era perspectiva se convertirá en Velázquez, una vez consumada esa muerte de la naturaleza, en perspectiva área: en la expresión del aire, el mejor símbolo de la ausencia.

¿Pero cuál es el contenido de esa intensidad que Velázquez refleja en el aire, en la perspectiva, y Cervantes y Shakespeare en la locura del sujeto? Acabamos de ver cómo para Descartes, más allá de su declaración plana, ese contenido es el fundamentum inconcussum de su filosofía. Hay un pasaje en la escena final del acto I de Hamlet, en el que cabe encontrar un cierto paralelismo con esa descripción cartesiana mediante la que reduce el yo hasta esa realidad última que es el fundamento de la ciencia y de la verdad moderna. Precisamente invocando al espectro y al efecto que le han producido su aparición y sus palabras, por tanto invocando esa subjetividad alternativa a la cartesiana y a la que nos hemos referido en términos de ficción y de locura, afirma Hamlet: «iQue me acuerde de ti...Borraré de mi memoria todo recuerdo trivial y vano, todas las sentencias de los libros, todas las ideas, todas las impresiones pasadas que copiaron allí la juventud y la observación!» (Shakespeare, 2003: 118). Estamos ante una reducción muy semejante a la llevada a cabo por la duda metódica, en la que se elimina todo el contenido de la conciencia, para quedarse con un reducto final, sólo que en este caso no es ese sustrato no susceptible de duda, no es el yo, sino el mandato, un mandato que procede del espectro: «Y sólo tu mandato vivirá en el libro de mi cerebro, sin mezcla de materia vil». Sobre ese mandato pivota la

10 En ese sentido no está de más recordar que Descartes no fue capaz de construir una ética y que se conformó con esa moral provisional que esbozó en el Discurso. 
obra, es su ejecución la que determina la trama, la que desencadena la tragedia, la que conduce la locura fingida, la que reconstruye el mundo en términos de tragedia del mismo modo que Descartes lo reconstruye en términos de ciencia. Es la voluntad, la voluntad del espectro y la del propio Hamlet, la que ocupa el lugar del cogito, voluntad de justicia y voluntad de verdad en ausencia y realizada finalmente desde la ficción, desde la representación de lo sucedido, aunando así a la verdad y a la justicia la belleza del arte.

No hay un pasaje análogo en Cervantes, o al menos yo no lo he encontrado, sin embargo cabría considerar que el escrutinio llevado a cabo por el barbero y el cura en la primera parte es en cierta medida un análogo. No deja de ser también una reducción, una valoración, pero inversa a la de Descartes, como inverso es el proceso que conduce a don Quijote a la locura. Porque, en efecto, allí donde Descartes va despojándose del buen sentido, de la visión ordinaria de las cosas que le presentan los sentidos, hasta llegar al muñón espiritual del yo, el héroe manchego se nos presenta como ya despojado de ellas para abrazarse al delirio desde el que refundar el mundo que vemos aparecer en sus peripecias. Pero en ambos el camino es circular, y ambos regresan a la cordura, sólo que dejándonos cada uno un viaje en el que está contenida la verdad, en el que el mundo respectivo ya no es el mismo para sus lectores, a pesar de que haya sido recobrado en su normalidad. Descartes recupera el mundo, pero ese mundo es el mundo reducido en el que la naturaleza como poema del ser se ha convertido en extensión donde no hay lugar para la belleza o la justicia. En cambio, cuando al final triste de la novela de Cervantes el protagonista regresa de la locura y se ve a sí mismo como cuerdo lo hace sancionando así sus aventuras, que siendo delirios y locuras, desembocan en lo que Unamuno llama Alonso Quijano el bueno. Es en ese final donde se encuentran de nuevo los distintos personajes y en el que está depositada a la vez la bondad y la belleza que sólo podían ser evocadas en la forma de ese viaje que el lector ya ha recorrido y que están en su memoria, evaporados también, cargados de melancolía, pero vivos como expresión de esa ausencia inefable que el viaje nos ha mostrado. Es el viaje, el discurso mismo, el que se desvela entonces como encerrando la verdad que culmina también en una subjetividad reconciliada en la figura de don Quijote yacente dictando sus últimas voluntades. El camino ha sido recorrido hasta el final, hasta la muerte con la que todo termina. Y nosotros, sus lectores, que lo hemos recorrido con él, muchos siglos después, seguimos meditando en torno a ello, confusos, atravesados por esa ausencia, y si conservamos ese punto de ingenuidad sin el cual es imposible cualquier aproximación al arte, podemos ver esa ausencia y ese espectro recorriendo el desierto de nuestra vida cotidiana e intuimos una vez más que allí habita la belleza. Al hacerlo asistimos de nuevo al nacimiento del arte moderno. En ese espectáculo y en esa ausencia hunde sus raíces la estética moderna. 


\section{BIBLIOGRAFÍA}

Adorno, T. y Horkheimer, M. (1998): Dialéctica de la Ilustración. Madrid: Trotta. Aristóteles (1970): El arte Poética. Madrid: Espasa-Calpe

Aristóteles (1982): Metafísica. Madrid: Gredos

Bloom, H. (2005): Genios. Un mosaico de cien mentes creativas y ejemplares. Bogotá: Norma.

Cervantes, M. (2003): Obras Completas. I. Madrid: Santillana.

Clarke, D.M. (1986): La filosofía de la ciencia de Descartes. Madrid: Alianza.

Derrida, J. (1989): Cogito e historia de la locura. En: La escritura y la diferencia. Barcelona: Anthropos.

Descartes, R. (1977): Meditaciones metafísicas. Madrid: Alfaguara.

Foucault, M. (1976): Historia de la locura. 2 vs. México: FCE.

Heidegger, M. (1989): Hölderlin y la esencia de la poesía. Barcelona: Anthropos

Koyré, A. (1990): Estudios galileanos. Madrid: Siglo XXI.

Madariaga, S. (1964): On Hamlet. Oxford: Routledge.

Popkin, R. (1983): Historia del escepticismo desde Descartes a Spinoza. México: FCE.

Quine, W. O. (2003): From a logical point of view: logico-philosophical essays. Cambridge: Harvard University Press.

Roiz, J. (1994): El poder de la ausencia. En: Revista de Estudios Politicos (Nueva época), 84, abril-junio, pp. 113-143.

Rorty, R. (1979): Philosophy and the Mirror on Nature. Princenton: Princenton Univesity Press.

Rinkus, J. J. (1975): Reflections on Turgenev's Hamlet and Don Quixote. En: Holzberger, W. G. y Waldeck, P. B. Perspectives on Hamlet: collected papers of the Bucknel Susquenna on Hamlet. London: Asociated University Press, pp. 74-99.

Shakespeare, W. (2003): Obras Completas. I Tragedias. Traducción de Manuel Astrana Marín. Madrid: Santillana.

Turró, S. (1985): Descartes. Del hermetismo a la nueva ciencia. Barcelona: Anthropos.

Unamuno, M. (1914): Vida de don Quijote y Sancho. Madrid: Renacimiento.

Varela Iglesias, F. Realismo e Idealismo en la recepción del Quijote (2007): En: Ertler, K. D. y Rodríguez Díaz, A. (Eds.). El Quijote hoy: la riqueza de su recepción. Frankfurt am Main/Madrid: Vevuert/ Iberoamericana, pp. 42-78.

Žižek, S. (2005): Bienvenidos al desierto de lo real. Madrid: Akal. 